\title{
Ten-year longitudinal study of thyroid function in children with Down's syndrome
}

Lorenzo Iughetti $^{\mathrm{a}}$, Barbara Predieri ${ }^{\mathrm{a}}$, Patrizia Bruzzi ${ }^{\mathrm{a}}$, Flavia Predieri ${ }^{\mathrm{a}}$, Giulia Vellani ${ }^{\mathrm{a}}$, Simona Filomena Madeo ${ }^{\mathrm{a}}$, Livia Garavelli ${ }^{\mathrm{b}}$, Ornella Biagioni ${ }^{\mathrm{c}}$, Giorgio Bedogni ${ }^{\mathrm{d}}$, Mauro Bozzola $^{e}$

${ }^{a}$ Department of Medical and Surgical Sciences of the Mother,Children and Adults, University of Modena and Reggio Emilia, Modena, Italy; ${ }^{\mathrm{b}}$ Clinical Genetics Unit, Obstetric and Pediatric Department, Istituto di Ricovero e Cura a Carattere Scientifico, Arcispedale Santa Maria Nuova, Reggio Emilia, Italy; ${ }^{\mathrm{c}}$ Department of Mental Health, AUSL, Modena, Italy; ${ }^{\mathrm{d}}$ Liver Research Center, Basovizza, Trieste, Italy and International Center for the Assessment of Nutritional Status (ICANS), University of Milan, Milan, Italy; ${ }^{\mathrm{e}}$ Internal Medicine and Therapeutics Department, University of Pavia, Italy.

ESPE membership: Lorenzo Iughetti, Mauro Bozzola

Short title: Thyroid dysfunction in Down's syndrome children

Type of manuscript: Original paper

Word count for the abstract: 200

Word count for the manuscript: 3127

Number of References: 46

Number of Tables: 2

\section{Number of Figures: 5}

Keywords: Thyroid function; Thyroid autoantibodies; Natural history; Down's syndrome;

Children

Financial disclosure: nothing to declare

\section{Address correspondence to:}

Lorenzo IUGHETTI, M.D., Ph.D.

Department of Medical and Surgical Sciences of the Mother, Children and Adults University of Modena and Reggio Emilia

Via del Pozzo, 71 - 41124 Modena, Italy

Phone: +39 059422 2182; Fax: +39 0594224583

E-mail: iughetti.lorenzo@unimore.it 


\begin{abstract}
Background/Aims The natural history of thyroid function in children with Down syndrome (DS) is relatively unknown We hypothesized that in these patients the occurrence of thyroid dysfunction rises during development.
\end{abstract}

Methods - Thyroid function was assessed yearly in 145 children with DS, all followed from birth up to 10 years of age. Heteroskedastic binary and ordinary logistic regression for repeated measures were used to evaluate the relationship of thyroid function with continuous time.

Results - Congenital hypothyroidism was detected in $7 \%$ of cases. The probability of acquired thyroid dysfunction increased from $30 \%$ at birth to $49 \%$ at 10 years $(p<0.001)$. The subclinical hypothyroidism (S-HT) was nearly stable during the follow-up. The probability of hypothyroidism increased from $7 \%$ to $24 \%$ at 10 years $(\mathrm{p}<0.001)$. Positive anti-thyroglobulin antibodies were associated with a higher odds of more severe hypothyroidism [odds ratio $(\mathrm{OR})=3.6]$. Positive anti-thyroid peroxidase antibodies (TPOab) were a better predictor of more severe hypothyroidism, $(\mathrm{OR}=6.1)$. Diffuse hypoechogenicity on thyroid ultrasound was found in 34 out of 145 children.

Conclusion - The probability of thyroid dysfunction increases during development is higher than previously reported. Such children should be carefully monitored annually to early identify thyroid dysfunction. 


\section{Introduction}

Down's syndrome (DS), the most common chromosomal disorder, is associated with several concomitant diseases, including thyroid dysfunction [1-3]. Thyroid disorders are more common in patients with DS than in the general population and they have been estimated to range between $4 \%$ and $19.5 \%$ [4-8] with an increase in frequency, up to $54 \%$, as the children age [5, 9-10]. These abnormalities include congenital hypothyroidism (1-3.6\%) [7, 11-14], primary hypothyroidism $(0.3-3.2 \%)$ [7, 14-15], autoimmune thyroiditis $(0.3-1.4 \%)$ [16], and subclinical hypothyroidism $(12.5-32.9 \%)$ [7, 10, 14-15, 17]. In addition, hyperthyroidism (0$2 \%$ ) occurs in children with DS as well $[7,10,18]$.

Pathogenesis, natural course, prognostic factors, and therapy of thyroid dysfunction in children with DS remain the objects of debate in the literature because epidemiological and long-term cohort studies are scarce. Pediatric endocrinologists frequently face the decision of what to do regarding these subjects.

In the general population the natural history of Hashimoto's thyroiditis in children and adolescents is not yet fully known. Thyroid-stimulating hormone concentrations showed large fluctuations over time, and a trend toward progressively deteriorating thyroid function was demonstrated [19-20]. A recent review on subclinical hypothyroidism in children showed that it is a remitting process with a rate of evolution toward overt hypothyroidism ranging between 0 and $28.8 \%$ [21].

We hypothesized that the occurrence of thyroid diseases in children with DS rises in the course of development. Therefore, we investigated the probability of each thyroid disease in a cohort of 145 children with DS from birth to 10 years of age. 


\section{Subjects and methods}

\section{Clinical and biochemical assessment.}

We conducted a cohort study from 1995 to 2010 including 205 Caucasian neonates with DS (95.6\% with primary trisomy $21,3.4 \%$ with translocation, and $1 \%$ with mosaicism) assessed at the Department of Pediatrics of the University of Modena and Reggio Emilia, Italy. Twenty neonates were not recruited because the parents refused the study, while during the follow-up children were excluded because of the development of severe heart disease in 18 cases, leukemia in 4 , seizure in 3 , and coeliac disease in 10 . We include this description of these subjects to avoid the lost to follow-up because of sudden death [22] and the diagnostic bias due to other exposure status. Specifically, patients with known autoimmune diseases [23] or using drugs that may interfere with thyroid function [24-25] are prone to develop autoimmune thyroiditis or subclinical hypothyroidism. Furthermore, 2 subjects refused to continue the study and 3 were lost to follow-up. Written informed consent was obtained from all parents at the moment of recruitment in the study and before the first data collection. The study was approved by the Ethics Committee of the University of Modena and Reggio Emilia.

Thyroid function status was tested annually from birth over a 10-year period. Blood samples were analyzed for thyroid-stimulating hormone (TSH), free thyroxine (F-T4), thyroglobulin antibody (TGab), and thyroid peroxidase antibody (TPOab) within the same laboratory. Plasma TSH and F-T4 were measured by fluorometric assay (AutoDELFIA automatic immunoassay system). TGab and TPOab were quantified by an immunometric assay (IMMULITE 2000): values $>40 \mathrm{IU} / \mathrm{ml}$ and $>35 \mathrm{IU} / \mathrm{ml}$ were defined as positive, respectively. Ultrasonography of thyroid gland was performed by an experienced pediatric radiologist who was blinded to the thyroid status of the subjects. In subjects with congenital hypothyroidism (C-HT) it was immediately performed while in the other ones it was 
firstly done at 2 years of age and repeated at time of thyroid dysfunction and/or thyroid autoantibodies development. In these cases a 2-year thyroid ultrasound follow-up was performed.

After exclusion of children with confirmed C-HT (newborn screening based on the measurement of $\mathrm{TSH} \geq 20 \mu \mathrm{IU} / \mathrm{ml}$ on eluates of dry blood collected on filter paper after $24 \mathrm{~h}$ of life as the primary screening test and confirmed by plasma thyroid function test performed after 8 days of life), all DS children were annually grouped according to both F-T4 and TSH levels as:

- euthyroidism (EuT): normal F-T4 and TSH $\leq 5 \mu \mathrm{IU} / \mathrm{ml}$

- hypothyroidism (HT): low F-T4 and TSH $\geq 10 \mu \mathrm{IU} / \mathrm{ml}$

- subclinical hypothyroidism (S-HT): normal F-T4 and TSH > $5 \mu \mathrm{IU} / \mathrm{ml}$

- hyperthyroidism (HyperT): high F-T4 and low TSH

Children with C-HT were excluded from the present prospective analysis, but not at first year evaluation of thyroid dysfunction probability.

Subjects with HT were treated with L-thyroxine and were considered in HT group during the whole follow up period. Replacement therapy was also started in children with SHT but only if TSH levels were persistently $\geq 10 \mu \mathrm{IU} / \mathrm{ml}[21]$ and these patients have always been included in the S-HT group.

\section{Statistical analysis}

Heteroskedastic binary and ordinal logistic regression for repeated measures were used to evaluate the changes of the binary and ordinal outcomes of interest with time [26-27]. These analyses were implemented using a heteroskedastic ordinal generalized linear model 
(OGLM) with cluster confidence intervals to take into account repeated measures. The

OGLM reduces to a logistic regression model when the outcome is binary and estimates the odds of more severe $v s$. less severe disease when the outcome is ordinal. The binary outcomes of interest were: 1$)$ thyroid dysfunction $(0=$ no; $1=$ yes $), 2)$ TGab positivity $(0=$ no; $1=$ yes $)$, TPOab positivity $(0=$ no; $1=$ yes $)$. The ordinal outcome of interest was hypothyroidism $(0=$ EuT, 1 = S-HT and, 2 = overt HT). Time was modeled as continuous (years, 1 to 10 by steps of 1) and the possibility to control for heteroskedasticy was used to model non-linear timeoutcome relationships. To test whether TGab and TPOab are associated with hypothyroidism we added them, first separately and then together, with time as predictors of the logistic ordinal model (multivariable analysis). The odds ratio (OR) associated with TGab and TPOab is a time-averaged measure of their association with hypothyroidism. Statistical significance was set to a value of $\mathrm{p}<0.05$. Statistical analysis was performed using STATA MP Version 13.0 . 


\section{Results}

From 1995-2010, 145 of 205 patients with DS were longitudinally evaluated for the purpose of the study. Overall, 59\% of the subjects were boys.

During the first year of evaluation, C-HT was confirmed in 10 of 145 cases $(6.9 \% ; 6$ out 10 had thyroid agenesis, 2 had thyroid ectopia and, 2 had thyroid hypoplasia), 4 children had HT (2.7\%; with normal thyroid ultrasound characteristics), 27 had S-HT (18.6\%; 2 out of 27 had thyroid hypoplasia and 1-year after developed thyroid autoantibodies), while the other 104 had normal thyroid function.

Figure 1 depicts the probability of any thyroid dysfunction during the study. Such probability increased from $30 \%(95 \%$ CI 24 to $37 \%)$ at $1^{\text {st }}$ year to $49 \%(41 \%$ to $58 \%)$ at $10^{\text {th }}$ year $(\mathrm{p}<0.001$, heteroskedastic binary logistic regression with cluster confidence intervals). Thyroid dysfunction was classified as HyperT in 1 case and as S-HT or overt HT in the remaining cases. Further analyses were performed on the subjects who did not develop HyperT.

Figure 2 depicts the probability of EuT, S-HT and overt HT during the follow-up. The probability of EuT decreased from $71 \%(65 \%$ to $78 \%)$ at $1^{\text {st }}$ year to $52 \%(44 \%$ to $60 \%)$ at $10^{\text {th }}$ year. S-HT had a fluctuating course between normal, compensated and overt HT so its probability was nearly stable, being $22 \%(17 \%$ to $28 \%)$ at $1^{\text {st }}$ year and $24 \%(17 \%$ to $31 \%)$ at $10^{\text {th }}$ year. Lastly, the probability of overt HT increased from $7 \%(3 \%$ to $10 \%)$ at $1^{\text {st }}$ year to $24 \%(17 \%$ to $32 \%)$ at $10^{\text {th }}$ year $(\mathrm{p}<0.001$, heteroskedastic ordinal logistic regression with cluster confidence intervals).

Considering the EuT group we found that, after 10 years, 64 patients still had normal function, 17 developed HT, and 22 developed S-HT. In the S-HT group one third developed 
EuT at the end of the study without replacement therapy, while one third developed HT. The thyroid dysfunctions were almost equally distributed between the genders (data not show).

Figures 3 and 4 depict the probability of positive thyroid autoantibodies (ATA) during the study. The probability of positive TGab increased from $3 \%(5 \%$ o to $5 \%)$ at $1^{\text {st }}$ year to $25 \%$ (17\% to $33 \%$ ) at $10^{\text {th }}$ year with corresponding figures of $5 \%$ (2\% to $7 \%$ ) and $37 \%$ (30\% to $45 \%)$ for TPOab $(\mathrm{p}<0.001$, heteroskedastic binary logistic regression with cluster confidence intervals) (Figure 3). The significant increase in the probability of ATA was mainly found in subjects with EuT (32 out of 99 initially negative, 32.3\%) and S-HT (14 out of 27 initially negative, 51.8\%) (Figure 4).

Combining the data according to thyroid function and the development of ATA, over a 10-year period, we found two different natural course patterns for both EuT and S-HT, mainly depending on the presence or absence of ATA. In particular, $60 \%$ of ATA-positive EuT subjects developed a thyroid dysfunction, whereas $73 \%$ of ATA-negative EuT cases remained in EuT group ( $\mathrm{p}=0.002$ ). Among children with S-HT at first visit, 50\% of ATA-positive cases had not changed at the last visit, whereas $28.6 \%$ developed HT. This prevalence was lower than in ATA-negative cases (38.5\%); only $21.4 \%$ of ATA-positive subjects developed EuT, in contrast to the $46.1 \%$ we found among the ATA-negative cases (Figure 5).

At multivariable ordinal logistic regression, TGab positivity was associated with an higher odds of more severe vs. less severe hypothyroidism but the estimate was imprecise $(\mathrm{OR}=3.6,95 \% \mathrm{CI} 1.2$ to $11.0, \mathrm{p}=0.02)$. On the contrary, TPOab positivity was strongly associated with more severe $v s$. less severe hypothyroidism (OR=6.1, 2.3 to $16.1, \mathrm{p}<0.001)$. Adding TGab to TPOab was associated with no improvement in the prediction of the severity of hypothyroidism as compared to TPOab alone (OGLM not shown). 
The characteristics of thyroid ultrasounds at the 10-year follow-up are reported in Table 1 . Overall, $62 \%$ of subjects had normal echogenicity on ultrasound and $23.5 \%$ had diffuse hypoechogenicity $(\mathrm{p}<0.001)$. The prevalence of thyroid dysfunctions in children with hypoechogenicity was significantly higher than in individuals with normal thyroid echogenicity (61.8\% vs. 37.8\%; $\mathrm{p}=0.028)$. Considering ATA status we found that subjects with hypoechogenicity had a significantly higher percentage of ATA positivity than those with normal echogenicity $(70.6 \%$ vs. $31.0 \%$; $\mathrm{p}<0.001)$. Interestingly, all subjects with diffuse hypoechogenicity on thyroid ultrasound but no circulating ATA $(29.4 \%)$ had thyroid dysfunctions (6 S-HT and 4 HT) (Table 2).

After exclusion of patients with C-HT, at the end of the follow-up $55(41 \%)$ of our children were treated for thyroid disorders. Specifically, L-thyroxine replacement therapy was started in all children who developed HT and in 24 out of $31(77.5 \%)$ patients with S-HT. Almost all patients with ATA-positive S-HT (88\%) required treatment in contrast to the $64 \%$ of ATA-negative cases. Methimazole was used for the only child with HyperT.

To assess the possibility that the level of initial TSH were predictive of a future $\underline{\text { thyroid dysfunction requiring L-thyroxine replacement therapy, we correlated the } 1^{\text {st }}}$ year TSH values with the last ones before beginning of the treatment. Excluding data from the C-HT patients and the 4 subjects already having HT at 1-year of life, the TSH levels at $1^{\text {st }}$ year $(4.92 \pm 1.83 \mu \mathrm{IU} / \mathrm{ml})$ and the ones just before therapy $(12.3 \pm 13.5 \mu \mathrm{IU} / \mathrm{ml})$ were not significantly correlated (Spearman $R=0.234, p=0.098)$. The same results were observed analyzing data according to $1^{\text {st }}$ year thyroid function: EuT (Spearman

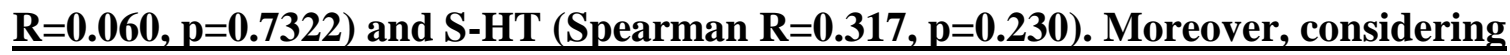
data from DS patients with S-HT at the end of the study, we found that both TSH 
$\underline{(\text { Spearman } R=-0.063, p=0.737) \text { and FT4 (Spearman } R=0.069, p=0.710) \text { levels were not }}$ significantly correlated with BMI z-score. 


\section{Discussion}

Several studies have investigated the prevalence of thyroid dysfunction in children and adults with DS [4, 10-12, 14-15, 28-29] but, to our best knowledge, this is the first prospective study to examine annually, over a 10-year period, the natural history of thyroid disorders in very young children with DS. Our data confirm the high probability of thyroid dysfunctions in children with DS, increasing year by year, when compared to reference ranges for the general population.

In our cohort, C-HT probability was higher than reported in the literature, ranging from $1 \%$ to $2.7 \%$ [11-13]. Early thyroid screening increases the prevalence of newborns demonstrating a modest elevation of blood spot TSH concentrations due to the physiological neonatal surge, increasing the number of false-positive results. Newborns with DS generally have a mild hypothyroid state because of decreased thyroxine concentration that left-shifted normal distribution and mildly elevated TSH levels [30]. To avoid false-positive C-HT due to early measurement, we used a TSH screening cut-off of $\geq 20 \mu \mathrm{IU} / \mathrm{ml}$ and this allowed us to exclude additional cases of C-HT that were mainly due to functional disorders [31]. Moreover, to confirm the positive screening C-HT cases we adopted a diagnostic algorithm that included the subsequent confirmation by low plasma FT4, high TSH levels and thyroid ultrasound characteristics (6 agenesis, 2 ectopia, and 2 hypoplasia).

Our children with DS suffered from two other different thyroid diseases such as S-HT mainly developed during the first 3 years of life and HT with a later onset; however, these thyroid dysfunctions were both present as early as the $1^{\text {st }}$ year of life. These cases of S-HT and HT, considering the thyroid ultrasound characteristics and the development of ATA, cannot be misdiagnosed with C-HT. Beyond the neonatal period, the incidence of elevated 
TSH values in DS increases, being reported as high as 85\% of infants under the age of 12 months [32].

Despite the limitation of the low number and the high heterogeneity of patients included in the published studies, in the general population S-HT is a benign and remitting process with a risk of progression to overt HT of approximately $0-12.5 \%$ [19, 21, 33-35]. In a retrospective multi-centre study [34], including a large pediatric cohort, it was demonstrated that TSH values tended to normalize proportionally to the degree of the TSH elevation at the initiation of the study. In subjects with TSH between 5.5 and $10 \mu \mathrm{IU} / \mathrm{ml}, 73.6 \%$ normalized their TSH, about $25 \%$ maintained that range, and about $2 \%$ had their TSH increased over 10 $\mu \mathrm{IU} / \mathrm{ml}$ but with normal FT4. In subjects with initially highly elevated TSH, $40 \%$ normalized their TSH, 33.1\% reduced their TSH to a value between 5.5 and $10 \mu \mathrm{IU} / \mathrm{ml}, 24.9 \%$ maintained their TSH higher than $10 \mu \mathrm{IU} / \mathrm{ml}$. Overall, $70.1 \%$ of initially abnormal TSH levels normalize in the second evaluation while HT requiring replacement therapy was found in $0.4 \%$ of the cohort.

In our cohort we found that an increase in TSH levels such to support the definition of S-HT is not correlated with BMI z-score and may be considered a common transient condition in DS and not necessarily imply the occurrence of HT. Considering our data, we recommend a careful approach and follow up for children with DS, thyroid hypoplasia and SHT, irrespective of the presence or absence of ATA. A recent study demonstrated that the distribution plot for TSH had a significant shift of the curve to higher values in subjects with DS respect to healthy controls, suggesting that hyperthyrotropinaemia is an innate attribute of chromosome 21 trisomy [36]. Moreover, some authors [5, 37-38] have proposed that S-HT is probably related to inappropriate secretion of TSH or thyroid insensitivity to $\mathrm{TSH}$, rather than to autoimmune thyroiditis. 
As well as an increase in the probability of thyroid dysfunction we also found an increased probability of ATA during the 10-year period. It is important to note that in our EuT children, the presence of ATA, mainly TPOab, significantly raised the risk of developing thyroid dysfunctions during the long-term follow-up. These data suggest that ATA might represent a marker of deteriorating thyroid function unlike $1^{\text {st }}$ year TSH levels that are not predicting for future thyroid dysfunction requiring therapy, both in initially EuT and SHT subjects with DS.

The prevalence of ATA in DS children was reported to range from $16 \%$ [38] to 39\% [39]. Moreover, the increased TSH levels were demonstrated to be positively correlated with TPOab which were already indicated as a key factor in the follow-up of DS subjects [40]. So, our results have confirmed the previously reported findings on the important role of both elevated TSH and ATA in the development of HT [10, 14, 16, 17, 39, 41], suggesting that children with DS should be tested more frequently than others.

In the general population it was demonstrated that in children and adolescents with both S-HT and autoimmune thyroiditis ATA increased over time [19, 35]. However, the progressive increase in TPOab raised the risk of developing HT by 3.5-fold [20], lower than data we found in our DS population.

Up to $10 \%$ of patients with autoimmune thyroiditis are ATA negative [42], so thyroid ultrasound findings may be important in order to differentiate children with a mild S-HT and autoimmune thyroiditis from those with other causes of thyroid dysfunction. Our data support the hypothesis that some children with DS may have a persistent mild HT presumably of thyroidal origin related to the trisomic state of chromosome 21 [43]. 
Thyroid hormones influence almost all aspects of normal development during childhood. They play a crucial role as regulators of neurodevelopment, growth and skeletal development, and metabolism [44]. The early diagnosis of thyroid dysfunctions is important and pediatricians can often recognize them in their early stages, by maintaining an appropriate index of suspicion. Recognition of HT can be very difficult because it has a subtle presentation and symptoms overlap with features of DS, including impaired intellectual development in young children, decreased linear growth, dry skin and fine hair, excess weight, dentition abnormalities, and decreased physical activity [2]. In our DS children with thyroid dysfunctions the incidence of replacement therapy was $41 \%$, over the 10 -year period. The medical treatment of S-HT is a topic of debate $[5,11,14]$; however, almost all patients with ATA required treatment [45]. Currently we do not know at which TSH level clinical signs and potential adverse effects on lipid profile, cardiac function, and neuropsychiatric performance will appear, or whether treatment can prevent them. However, it was demonstrated that S-HT, even of many years' duration, and HT, if appropriately treated within a few months, do not impair growth [19]. In the general pediatric population, there is no clear evidence of the beneficial effects of L-thyroxine on growth and thyroid volume [21], but van Trotsenburg et al. [46] have reported that in children with DS replacement therapy for the first 24 months of life probably results in improvements of psychomotor development and growth. However, this study was designed to determine the rate of annual thyroid dysfunctions in this population, not the appropriateness of treatment.

In summary, in our study thyroid dysfunctions were relatively common in children with DS and, because symptoms might be mistaken for symptoms related to the natural course of DS, they may represent a significant health risk if not identified. We suggest that DS patients, especially those with EuT or S-TH associated with positive ATA, should be 
annually monitored to precociously identify thyroid diseases and to begin an adequate replacement therapy when proper. 


\section{References}

1. Radetti G, Drei F, Betterle C, Mengarda G: Down's syndrome, hypothyroidism and insulin-dependent diabetes mellitus. Helv Paediatr Acta 1986;41:377-380.

2. Prasher VP: Down syndrome and thyroid disorders: a review. Downs Syndr Res Pract 1999;6:25-42.

3. Weijerman ME, de Winter JP: Clinical practice. The care of children with Down syndrome. Eur J Pediatr 2010;169:1445-1452.

4. Pueschel SM, Jackson IM, Giesswein P, Dean MK, Pezzullo JC: Thyroid function in Down syndrome. Res Dev Disabil 1991;12:287-296.

5. Gibson PA, Newton RW, Selby K, Price DA, Leyland K, Addison GM: Longitudinal study of thyroid function in Down's syndrome in the first two decades. Arch Dis Child 2005;90:574-578.

6. Murphy J, Philip M, Macken S, Meehan J, Roche E, Mayne PD, O'Regan M, Hoey HM: Thyroid dysfunction in Down's syndrome and screening for hypothyroidism in children and adolescents using capillary TSH measurement. J Pediat Endocrinol Metab 2008;21:155-163.

7. Regueras L, Prieto P, Muñoz-Calvo MT, Pozo J, Arguinzoniz L, Argente J: Endocrinological abnormalities in 1.105 children and adolescents with Down syndrome. Med Clin (Barc) 2011;136:376-381.

8. McGowan S, Jones J, Brown A, Reynolds L, Leyland K, Charleton P, Rahim M, Mansor M, Ritha S, Donaldson M, Scottish Down Syndrome Thyroid Screening Group: Capillary TSH screening programme for Down's syndrome in Scotland, 1997-2009. Arch Dis Child 2011;96:1113-1117. 
9. Kishnani PS, Crissman BG: Special issue: current perspectives on Down syndrome: selected medical and social issues. Am J Med Genet C Semin Med Genet 2006;142C:127205.

10. Unachak K, Tanpaiboon P, Pongprot Y, Sittivangkul R, Silvilairat S, Dejkhamron P, Sudasna J: Thyroid functions in children with Down's syndrome. J Med Assoc Thai 2008;91:56-61.

11. Fort P, Lifshitz F, Bellisario R, Davis J, Lanes R, Pugliese M, Richman R, Post EM, David R: Abnormalities of thyroid function in infants with Down syndrome. J Pediatr 1984;104:545-549.

12. Cutler AT, Benezra-Obeiter R, Brink SJ: Thyroid function in young children with Down syndrome. Am J Dis Child 1986;140:479-483.

13. Jaruratanasirikul S, Patarakijvanich N, Patanapisarnsak C: The association of congenital hypothyroidism and congenital gastrointestinal anomalies in Down's syndrome infants. J Pediatr Endocrinol Metab 1998;11:241-246.

14. Tüysüz B, Beker DB: Thyroid dysfunction in children with Down's syndrome. Acta Paediatr 2001;90:1389-1393.

15. Shaw CK, Thapalial A, Nanda S, Shaw P: Thyroid dysfunction in Down syndrome. Kathmandu Univ Med J (KUMJ) 2006;4:182-186.

16. Karlsson B, Gustafsson J, Hedov G, Ivarsson SA, Annerén G: Thyroid dysfunction in Down's syndrome: relation to age and thyroid autoimmunity. Arch Dis Child 1998;79:242-245.

17. Rubello D, Pozzan GB, Casara D, Girelli ME, Boccato S, Rigon F, Baccichetti C, Piccolo M, Betterle C, Busnardo B: Natural course of subclinical hypothyroidism in Down's syndrome: prospective study results and therapeutic considerations. J Endocrinol Invest 1995;18:35-40. 
18. Goday-Arno A, Cerda-Esteva M, Flores-Le-Roux JA, Chillaron-Jordan JJ, Corretger JM, Cano-Pérez JF: Hyperthyroidism in a population with Down syndrome (DS). Clin Endocrinol (Oxf) 2009;71:110-114.

19. Radetti G, Gottardi E, Bona G, Corrias A, Salardi S, Loche S, Study Group for Thyroid Diseases of the Italian Society for Pediatric Endocrinology and Diabetes (SIEDP/ISPED): The natural history of euthyroid Hashimoto's thyroiditis in children. J Pediatr 2006;149:827-832.

20. Radetti G, Maselli M, Buzi F, Corrias A, Mussa A, Cambiaso P, Salerno M, Cappa M, Baiocchi M, Gastaldi R, Minerba L, Loche S: The natural history of the normal/mild elevated TSH serum levels in children and adolescents with Hashimoto's thyroiditis and isolated hyperthyrotropinaemia: a 3-year follow-up. Clin Endocrinol (Oxf) 2012;76:394398.

21. Monzani A, Prodam F, Rapa A, Moia S, Agarla V, Bellone S, Bona G: Natural history of subclinical hypothyroidism in children and adolescents and potential effects of replacement therapy: a review. Eur J Endocrinol 2012;168:R1-R11.

22. Myrelid A, Jonsson B, Guthenberg C, von Döbeln U, Annerén G, Gustafsson J: Increased neonatal thyrotropin in Down syndrome. Acta Paediatr 2009;98:1010-1013.

23. Elfström P, Montgomery SM, Kämpe O, Ekbom A, Ludvigsson JF: Risk of thyroid disease in individuals with celiac disease. J Clin Endocrinol Metab 2008;93:3915-3921.

24. Kim SH, Chung HR, Kim SH, Kim H, Lim BC, Chae JH, Kim KJ, Hwang YS, Hwang H: Subclinical hypothyroidism during valproic acid therapy in children and adolescents with epilepsy. Neuropediatrics 2012;43:135-139.

25. van Santen HM, Thonissen NM, de Kraker J, Vulsma T: Changes in thyroid hormone state in children receiving chemotherapy. Clin Endocrinol (Oxf) 2005;62:250-257. 
26. Hilbe JM: Generalized linear models and extensions. College Station, Tex.: Stata Press; 2012.

27. Williams R: Fitting heterogeneous choice models with oglm. Stata Journal 2010;10:540567.

28. Loudon MM, Day RE, Duke EM: Thyroid dysfunction in Down's syndrome. Arch Dis Child 1985;60:1149-1151.

29. Prasher V, Ninan S, Haque S: Fifteen-year follow-up of thyroid status in adults with Down syndrome. J Intellect Disabil Res 2011;55:392-396.

30. van Trotsenburg ASP, Vulsma T, van Santen HM, Cheung W, de Vijlder JJM: Lower neonatal screening thyroxine concentrations in Down Syndrome newborns. J Clin Endocrinol Metab 2003;88:1512-1515.

31. Deladoëy J, Ruel J, Giguère Y, Van Vliet G: Is the incidence of congenital hypothyroidism really increasing? A 20 -year retrospective population-based study in Québec. J Clin Endocrinol Metab 2011;96:2422-2429.

32. Sharav T, Collins R, Baab P: Growth studies in infants and children with Down's syndrome and elevated levels of thyrotropin. Am J Dis Child 1988;142:1302-1306.

33. Surks MI, Ortiz E, Daniels GH, Sawin CT, Col NF, Cobin RH, Franklyn JA, Hershman JM, Burman KD, Denke MA, Gorman C, Cooper RS, Weissman NJ: Subclinical thyroid disease: scientific review and guidelines for diagnosis and management. JAMA 2004;291:228-238.

34. Lazar L, Frumkin RB, Battat E, Lebenthal Y, Phillip M, Meyerovitch J: Natural history of thyroid function tests over 5 years in a large pediatric cohort. Endocrinol Metab 2009;94:1678-1682. 
35. Zois C, Stavrou I, Svarna E, Seferiadis K, Tsatsoulis A: Natural course of autoimmune thyroiditis after elimination of iodine deficiency in northwestern Greece. Thyroid 2006;16:289-293.

36. Meyerovitch J, Antebi F, Greenberg-Dotan S, Bar-Tal O, Hochberg Z:

Hyperthyrotropinaemia in untreated subjects with Down's syndrome aged 6 months to 64 years: a comparative analysis. Arch Dis Child 2012;97:595-598.

37. Selikowitz M: A five-year longitudinal study of thyroid function in children with Down syndrome. Dev Med Child Neurol 1993;35:396-401.

38. Faria CD, Ribeiro S, Kochi C, Silva AP, Ribeiro BN, Marçal LT, Santos FH, Eduardo CP, Monte O, Longui CA: TSH neurosecretory dysfunction (TSH-nd) in Down syndrome (DS): low risk of progression to Hashimoto's thyroiditis. Arq Bras Endocrinol Metabol 2011;55:628-631.

39. Ivarsson SA, Ericsson UB, Gustafsson J, Forslund M, Vegfors P, Annerén G: The impact of thyroid autoimmunity in children and adolescents with Down syndrome. Acta Paediatr 1997;86:1065-1607.

40. Dias VM, Nunes JC, Araújo SS, Goulart EM: Etiological assessment of hyperthyrotropinemia in children with Down's syndrome. J Pediatr (Rio J) 2005;81:79-84.

41. Freeman SB, Torfs CA, Romitti MH, Royle MH, Druschel C, Hobbs CA, Sherman SL: Congenital gastrointestinal defects in Down syndrome: a report from the Atlanta and National Down Syndrome Projects. Clin Genet 2009;75:180-184.

42. Cappa M, Bizzarri C, Crea F: Autoimmune Thyroid Diseases in Children. J Thyroid Res 2011;2011:675-703.

43. van Trotsenburg AS, Kempers MJ, Endert E, Tijssen JG, de Vijlder JJ, Vulsma T: Trisomy 21 causes persistent congenital hypothyroidism presumably of thyroidal origin. Thyroid 2006;16:671-680. 
44. Roberts CGP, Ladenson PW: Hypothyroidism. Lancet 2004;363:793-803.

45. Popova G, Paterson WF, Brown A, Donaldson MD: Hashimoto's thyroiditis in Down's syndrome: clinical presentation and evolution. Horm Res 2008;70:278-284.

46. van Trotsenburg ASP, Vulsma T, van Rozenburg-Marres SL, van Baar AL, Ridder JC, Heymans HS, Tijssen JG, de Vijlder JJ: The effect of thyroxine treatment started in the neonatal period on development and growth of two-year-old Down syndrome children: a randomized clinical trial. J Clin Endocrinol Metab 2005;90:3304-3311. 


\section{Figures}

Figure 1. Thyroid function: probability of any thyroid dysfunction (excluding CHT).

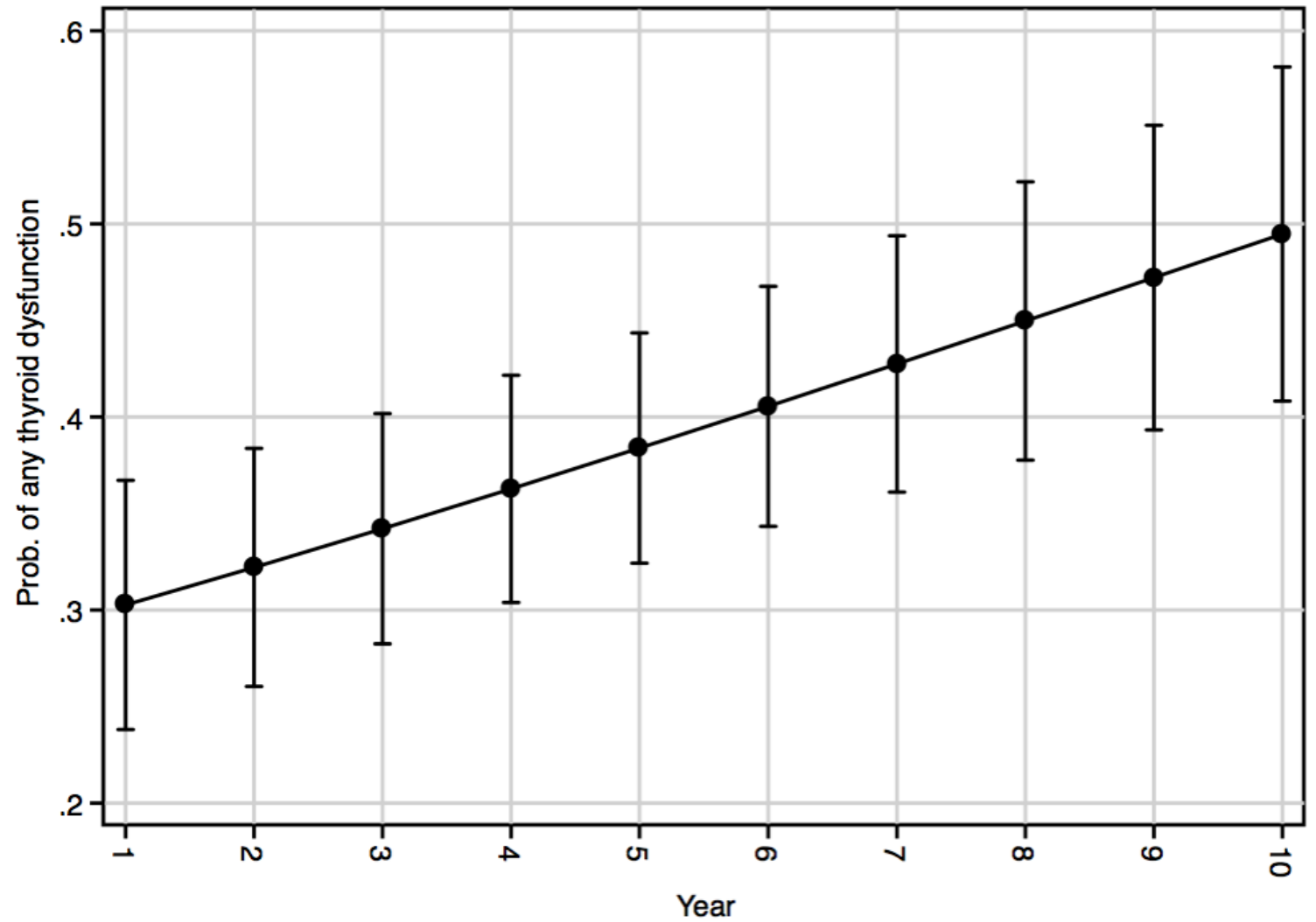


Figure 2. Thyroid function: probability of EuT, S-HT, and HT.
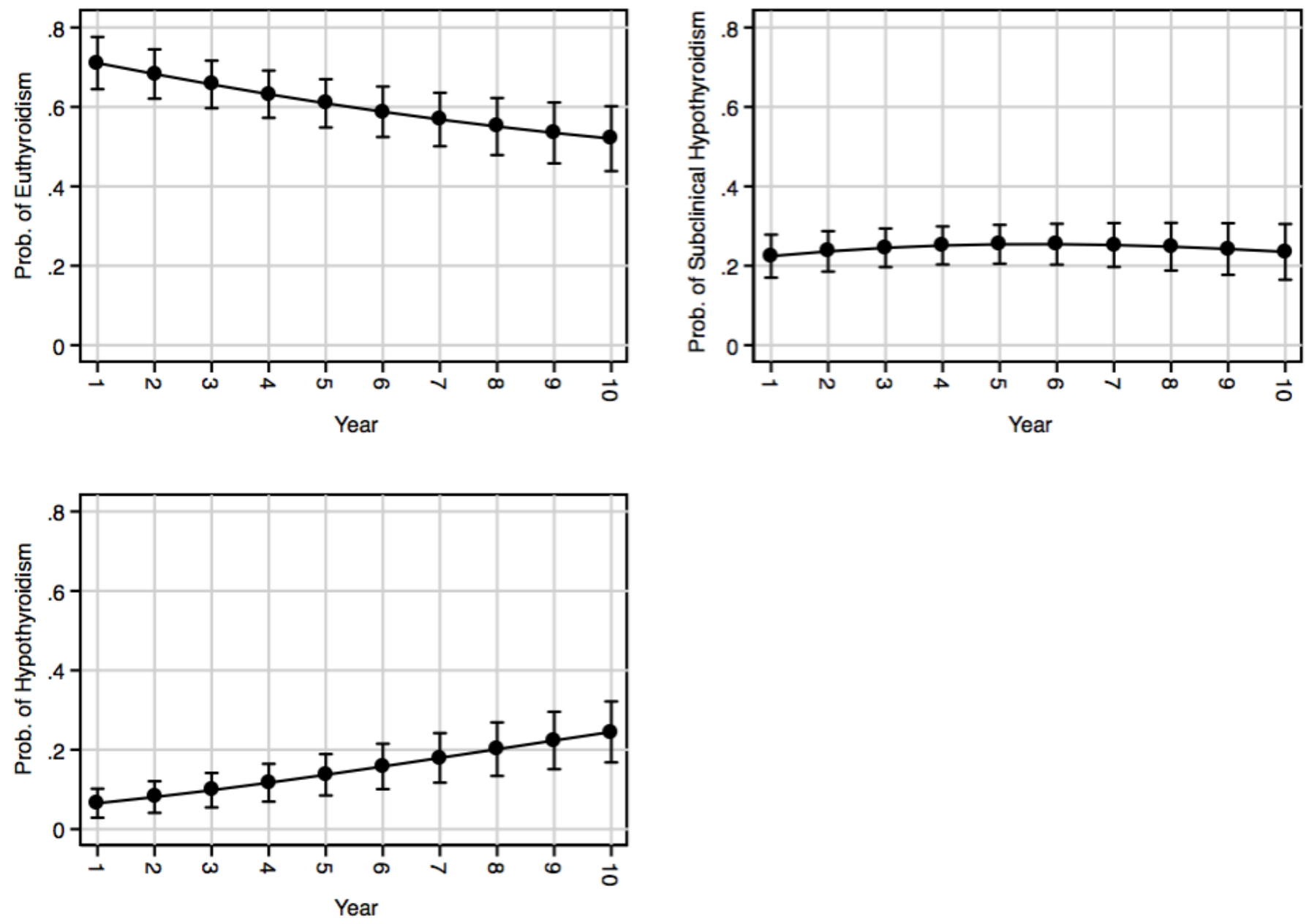
Figure 3. Anti-thyroid antibodies: probability of positive TGab and TPOab.
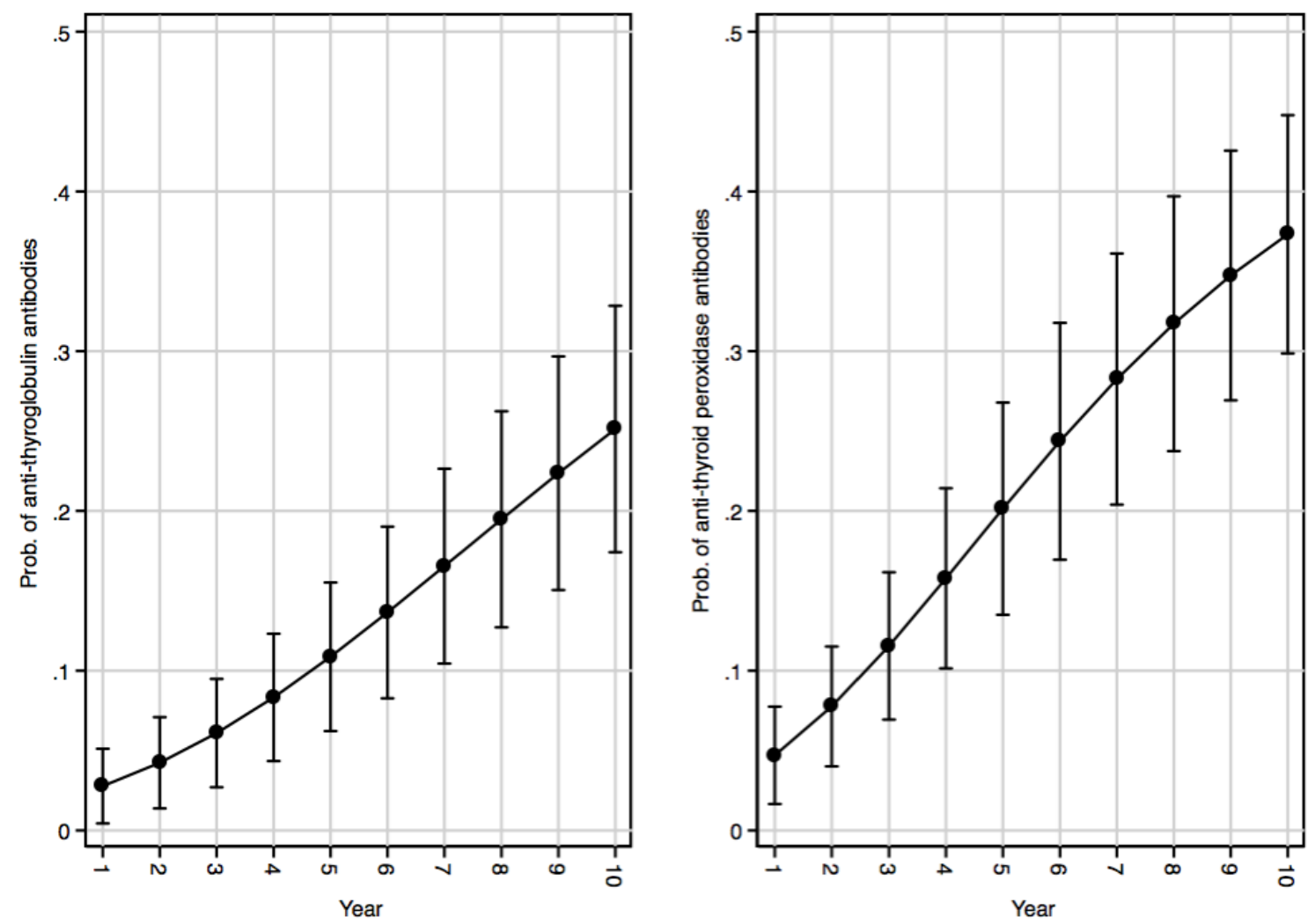
Figure 4. Anti-thyroid antibodies: changes of TGab and TPOab according to thyroid status

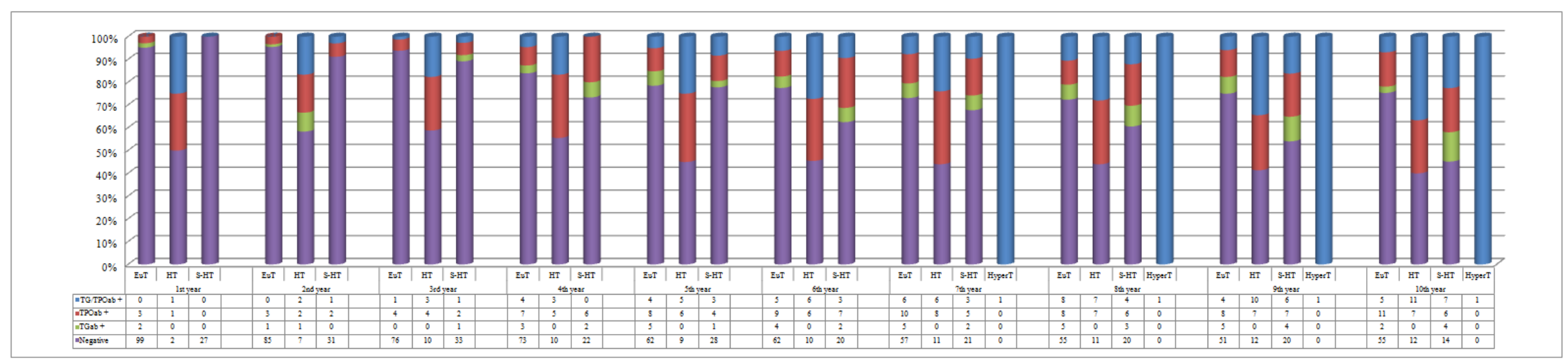




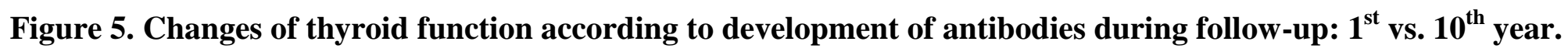

$\square$ 10th year EuT (73) $\quad$ 10th year HT (30) $\square 10$ th year S-HT (31) $\square 10$ th year HyperT (1)

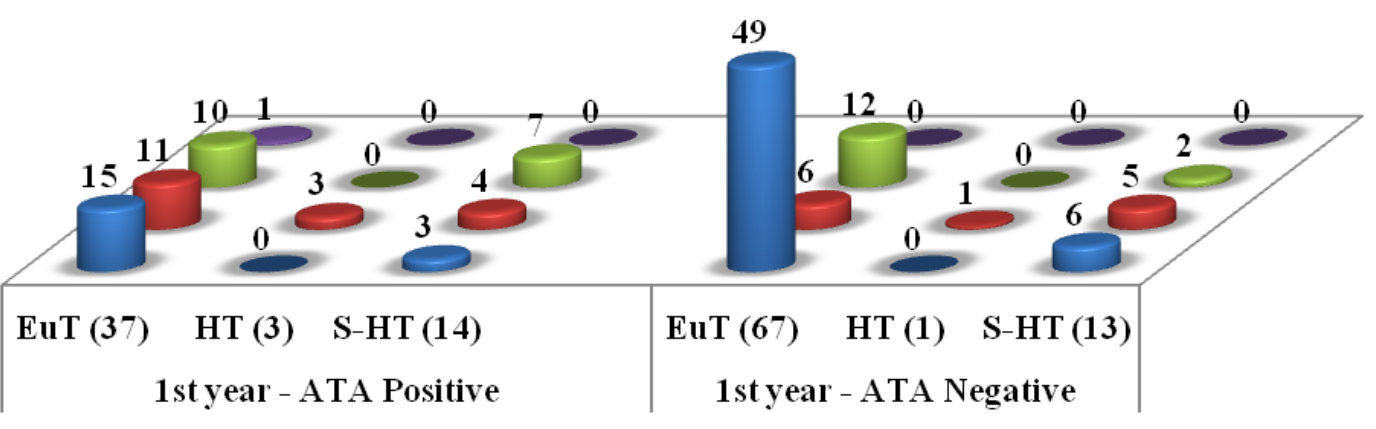


Tables.

Table 1. Thyroid ultrasound characteristics according to thyroid status at $10^{\text {th }}$ years.

\begin{tabular}{|c|c|c|c|c|c|}
\hline \multirow{2}{*}{$\begin{array}{l}\text { Thyroid ultrasound characteristics at } 10^{\text {th }} \text { years } \\
\text { ATA status at } 10^{\text {th }} \text { years }\end{array}$} & \multicolumn{5}{|c|}{ Thyroid status at $10^{\text {th }}$ years } \\
\hline & EuT (73) & C-HT (10) & HT (30) & S-HT (31) & HyperT (1) \\
\hline Normal (90) & $56(76.7 \%)$ & -- & $17(56.7 \%)$ & $17(54.8 \%)$ & -- \\
\hline ATA positive $(28 / 90)$ & $10(13.7 \%)$ & -- & $8(26.7 \%)$ & $10(32.3 \%)$ & -- \\
\hline Hypoplasia (12) & $4(5.5 \%)$ & $2(20 \%)$ & $2(6.6 \%)$ & $4(13.0 \%)$ & -- \\
\hline ATA positive (1/12) & -- & -- & -- & $1(3.2 \%)$ & -- \\
\hline Agenesis (6) & -- & $6(60 \%)$ & -- & -- & -- \\
\hline Ectopia (2) & -- & $2(20 \%)$ & -- & -- & -- \\
\hline Nodule (1) & -- & -- & -- & $1(3.2 \%)$ & -- \\
\hline ATA positive (1/1) & -- & -- & -- & $1(3.2 \%)$ & -- \\
\hline Diffuse hypoechogenicity (34) & $13(17.8 \%)$ & -- & $11(36.7 \%)$ & $9(29.0 \%)$ & $1(100 \%)$ \\
\hline ATA positive (24/34) & $13(17.8 \%)$ & -- & $7(23.3 \%)$ & $3(9.7 \%)$ & $1(100 \%)$ \\
\hline
\end{tabular}

Data are reported as $\mathrm{n}$. of subjects and \% according to thyroid status 
Table 2. Thyroid autoantibodies (ATA) status according to thyroid ultrasound characteristics during the 10-years follow-up.

\begin{tabular}{|c|c|c|c|c|c|}
\hline \multirow{2}{*}{$\begin{array}{l}\text { Thyroid ultrasound characteristics } \\
10^{\text {th }} \text { years }\end{array}$} & \multirow{2}{*}{$\begin{array}{c}\text { Thyroid status } \\
10^{\text {th }} \text { years }\end{array}$} & \multicolumn{4}{|c|}{ ATA status at $10^{\text {th }}$ years } \\
\hline & & TG/TPOab + (24) & $\mathrm{TPOab}+(24)$ & $\mathrm{TGab}+(6)$ & Negative (81) \\
\hline \multirow[t]{4}{*}{ Normal (90) } & & $4(4.4 \%)$ & $20(22.2 \%)$ & $4(4.4 \%)$ & $62(69.0 \%)$ \\
\hline & EuT & $2(2.2 \%)$ & $8(8.9 \%)$ & -- & $46(51.2 \%)$ \\
\hline & HT & $1(1.1 \%)$ & $7(7.8 \%)$ & -- & $9(10 \%)$ \\
\hline & S-HT & $1(1.1 \%)$ & $5(5.5 \%)$ & $4(4.4 \%)$ & $7(7.8 \%)$ \\
\hline \multirow[t]{4}{*}{ Hypoplasia (10) } & & -- & $1(10 \%)$ & -- & $9(90 \%)$ \\
\hline & EuT & -- & -- & -- & $4(40 \%)$ \\
\hline & HT & -- & -- & -- & $2(20 \%)$ \\
\hline & S-HT & -- & $1(10 \%)$ & -- & $3(30 \%)$ \\
\hline \multirow[t]{2}{*}{ Nodule (1) } & & $1(100 \%)$ & -- & -- & -- \\
\hline & S-HT & $1(100 \%)$ & -- & -- & -- \\
\hline \multirow[t]{5}{*}{ Diffuse hypoechogenicity (34) } & & $19(55.9 \%)$ & $3(8.8 \%)$ & $2(5.9 \%)$ & $10(29.4 \%)$ \\
\hline & EuT & $8(23.6 \%)$ & $3(8.8 \%)$ & $2(5.9 \%)$ & -- \\
\hline & HT & $7(20.6 \%)$ & -- & -- & $4(11.8 \%)$ \\
\hline & S-HT & $3(8.8 \%)$ & -- & -- & $6(17.6 \%)$ \\
\hline & HyperT & $1(2.9 \%)$ & -- & -- & -- \\
\hline
\end{tabular}

Data are reported as n. of subjects and \% according to thyroid ultrasound characteristics (patients with C-HT were all negative for ATA so their data were excluded from the table) 